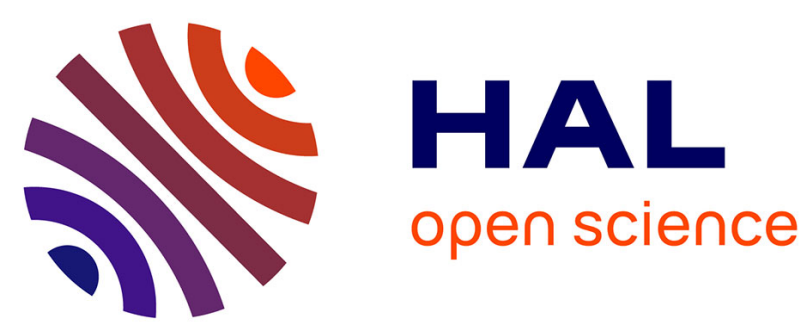

\title{
Advances in representation and analysis of mono and multi-intake Temporal Dominance of Sensations data
}

Mara V. V. Galmarini, Michel Visalli, Pascal Schlich

\section{To cite this version:}

Mara V. V. Galmarini, Michel Visalli, Pascal Schlich. Advances in representation and analysis of mono and multi-intake Temporal Dominance of Sensations data. Food Quality and Preference, 2017, 56 (Part B), pp.247-255. 10.1016/j.foodqual.2016.01.011 . hal-01426953

\section{HAL Id: hal-01426953 \\ https://u-bourgogne.hal.science/hal-01426953}

Submitted on 6 Oct 2017

HAL is a multi-disciplinary open access archive for the deposit and dissemination of scientific research documents, whether they are published or not. The documents may come from teaching and research institutions in France or abroad, or from public or private research centers.
L'archive ouverte pluridisciplinaire HAL, est destinée au dépôt et à la diffusion de documents scientifiques de niveau recherche, publiés ou non, émanant des établissements d'enseignement et de recherche français ou étrangers, des laboratoires publics ou privés. 


\title{
Advances in representation and analysis of mono and multi-intake Temporal Dominance of Sensations data
}

\author{
M.V. Galmarini ${ }^{\mathrm{a}, \mathrm{b}, \mathrm{c}, *}$, M. Visalli ${ }^{\mathrm{a}}$, P. Schlich ${ }^{\mathrm{a}}$ \\ a INRA, UMR1324 Centre des Sciences du Goût et de l'Alimentation, Dijon, France \\ b Consejo Nacional de Investigaciones Científicas y Técnicas, Buenos Aires, Argentina \\ ${ }^{c}$ Facultad de Ciencias Agrarias, Pontificia Universidad Católica Argentina, Buenos Aires, Argentina
}

\begin{abstract}
Using the concept of dominance, other than intensity, Temporal Dominance of Sensations (TDS) has become a highly used temporal descriptive technique providing information on sequentiality and duration time of dominant sensations. In the present work we propose: (i) a new graphical tool for representing the sequentiality of (multi-intake) TDS data and (ii) an inferential approach to data analysis based on duration of dominance. TDS data are generally presented as TDS curves. However, visual inspection and curve comparison among intakes of a same product, several products or both, can be a cumbersome task. To better show sequentiality of dominant attributes, we propose different TDS band-plots. These representations show whether attributes are dominant or not (at panel level) allowing the follow-up of each descriptor and improving visual comparison of products. Nonetheless, visual assessment is not enough to determine significant differences. Using the total duration of dominance of each attribute, three-way ANOVA's including subject, product and intake as factors, together with their two-way interactions, with subject as random effect can be performed. This test reveals if a certain attribute is dominant for a significantly longer or shorter period of time in some products, as well as its changes over intakes. Interaction between product and intake becomes highly important to see if evolution over intakes is the same for all the products. Further, multidimensional differences can be summarized over attributes by a MANOVA and represented by a Canonical Variate Analysis (CVA), allowing the comparison of different intakes of a same product, or different products, or altogether.
\end{abstract}

\author{
Keywords: \\ TDS \\ Multi-intake \\ Bandplot \\ ANOVA \\ MANOVA \\ CVA
}

\section{Introduction}

Temporal Dominance of Sensations (TDS) is a temporal multidimensional sensory method (Pineau, Cordelle, \& Schlich, 2003). It consists in presenting to the assessors a list of descriptors from which they are asked to choose at every moment of consumption the one which they consider dominant (the most striking perception at a given time, not necessarily the most intense one (Pineau et al., 2009)). Without the need of quantification, this qualitative, temporal technique provides an intuitive response which needs less training since no scaling is used. This somewhat playful approach is one of the reasons which facilitated extending this technique to working with consumers (Brachet et al., 2014; Schlich, 2013; Thomas, Visalli, Cordelle, \& Schlich, 2015) and also to the evaluation of successive intakes such as multi-bite

* Corresponding author at: Facultad de Ciencias Agrarias, Pontificia Universidad Católica Argentina, Cap Gral. Ramon Freire 183, 1426 Buenos Aires, Argentina. E-mail address: mgalmarini@gmail.com (M.V. Galmarini).
(Schlich, Pineau, Urbano, \& Visalli, 2013) or multi-sip (Zorn, Alcaire, Vidal, Giménez, \& Ares, 2014). This multi-intake approach could be key towards better interpreting the sensory perception of a whole food portion. However, it also means that more information is obtained therefore needing different ways of representation and analysis.

TDS data is generally represented by curves (Pineau et al., 2009) of rate of dominance at panel level of each attribute against time (standardized or not). These curves are rich in information and their visual inspection is the base for product description (Marcano, Varela, Cunha, \& Fiszman, 2015; Zorn et al., 2014). However, when working with multiple products and also multiple intakes, the amount of curves multiply quickly and visual comparison becomes a cumbersome task. Working with multiple sips of sweet solutions, Zorn et al. (2014) attempted to simplify the representation by plotting TDS curves which included all products but represented only one attribute (e.g. description of the dominance rate of sweetness with the different lines represent the evaluated products). This is a somewhat practical approach, but by reducing 
the presented information the global image of all products and sips comparison was lost. Another way of graphical comparison used for TDS data includes difference curves (Pineau \& Schlich, 2014) which allow the comparison of two different products. But this is a one-on-one comparison which implies that with as little as 4 products evaluated over 3 sips, the amount of difference curves of interest could amount to 18 . In this way, being the visual representation of sequentiality of dominant sensations so important in TDS data, new graphical tools are needed for better summarize the obtained information. Taking this into account, in the present paper a different way of representing the sequentiality of TDS data is proposed aiming to facilitate the observation of the evolution of the descriptors over time as well as product differences. It is to be noted that it is not the aim of the present paper to present a statistical tool to analyze the succession of cited sensations as could be found in Castura and Li (2016).

Also based on TDS curves, different authors have suggested statistical tests using parameters which characterize the curves as in Time-Intensity (T-I) data analysis (Bruzzone, Ares, \& Giménez, 2013; Cadena, Vidal, Ares, \& Varela, 2014; Pineau \& Schlich, 2014; Rodrigues, Condino, Pinheiro, \& Nunes, 2016). Nonetheless, it should be kept in mind that dominance rate represents the agreement on dominance at panel level at a given moment of tasting (Lenfant, Loret, Pineau, Hartmann, \& Martin, 2009) which is different from intensity as in T-I curves. Moreover, when using the parameter of the area under the curve the temporal aspect of the data is removed (Di Monaco, Su, Masi, \& Cavella, 2014).

Another approach to TDS data analysis has been proposed by Meyners and Pineau (2010) who introduced a randomization test based on distances between matrices. For this purpose, TDS sequences were unfolded to data matrices with a single non-zero entry per time point (column) proposing pair-wise comparisons and inference by attribute or time point. Unfortunately, this test needs long computing times and is dependent on the randomization used limiting its practical application.

More recently, several authors have proposed a univariate approach to analyze TDS data based on different ways of splitting the time of the evaluation into time intervals (Devezeaux De Lavergne, Van Delft, Van De Velde, Van Boekel, \& Stieger, 2015; Hutchings, Foster, Grigor, Bronlund, \& Morgenstern, 2014; Hutchings, Foster, Hedderley, \& Morgenstern, 2014; Lepage et al., 2014). Using time intervals allows applying the concept of sensory trajectory to TDS data which has already been well documented (Devezeaux De Lavergne et al., 2015; Lenfant et al., 2009). However, determining time periods as a pre-treatment for ANOVA tests can be tricky since there is no rule of thumb to decide the number of time periods. Moreover, it is very likely that the attribute chosen at time $t+1$ will be the same as the one chosen at time $t$, which makes time points data auto correlated as well, i.e. not independent and this dependency is less strong on pre-processed data (Lepage et al., 2014). Taking all this into consideration, and looking for a simpler tool for data analysis, in the present paper we propose an inferential approach based on individual total duration of dominant attributes, including also the multiple intakes as factors. For an illustrative purpose, the different forms of analysis will be presented using a data set from a multi-sip TDS on wine. It should be kept in mind that the characterization of these products is not the main interest of the present paper and that, given the product used as an example, the word sip will be generally used when talking about intake.

\section{Acquisition of the data set used as example}

The data set used for an illustrative purpose was acquired by a multi-sip TDS evaluation of four different wines, as part of a wine sensory characterization project. A brief description of the wine samples used is presented in Table 1.

Product evaluation was carried out by a total of 31 frequent wine consumers from the city of Dijon (Burgundy region), France. They were recruited by means of an on-line questionnaire based on their frequency of consumption of red, dry white and rosé wines. Other conditions included their availability and willingness to participate as well as having no food allergies. The final group was composed of 15 males and 16 women, aged between 27 and 67 years-old (mean of 52) and they were economically gratified for their participation in the study. They attended a total of three tasting sessions. The first one was for the purpose of familiarizing them with the method and the proposed descriptors. References for sour ( $0.08 \%$ citric acid solution), bitter ( $0.05 \%$ caffeine solution), sweet ( $2 \%$ sucrose solution) and astringent (concentrated green tea) were presented coded with a three-digit number and consumers were asked to try them and state the sensation perceived while drinking each solution. Afterwards they were presented the olfactory references and they were explained that they represented the different aromatic families, e.g.: for floral they were presented a violet scent but they were instructed that any aroma in relation to other flowers such as roses, gardenias, etc., could be considered as floral. Over the other two sessions (one-hour long each) consumers described the four wine samples (having evaluated them in duplicate by the end of the study) by multi-sip TDS.

The tasting protocol for each sample was the same. Consumers were instructed to click on the "START" button as soon as they had the wine sample in their mouth. They could then successively select the attribute that most triggered their attention from a list of 11 descriptors (Fig. 1). Only one attribute could be selected at each time, but they were free to select an attribute several times and they could continue to describe their perception until no sensation was dominant. At this point, they clicked on the "STOP" button to indicate the end of the TDS evaluation of this sip. There was no time limit for each sample evaluation, which is important for data evaluation since each sip could have a different duration. After this, consumers performed the same task for the second and third sip. In this way three TDS profiles were obtained for each wine and each consumer. The same list of descriptors was used for all samples.

For each sample $3 \mathrm{cl}$ of wine were presented in coded (threedigit random numbers) black wine glasses, in a monadic way following a Williams presentation. Consumers were instructed to pay special attention to the amount consumed in each sip in order to take approximately the same quantity of wine each time $(\approx 1 \mathrm{cl})$. Nonetheless, the volume of the sip was not further controlled in order to have a more natural consumption. The 31 consumers evaluated all four samples per session (total of $12 \mathrm{cl}$ of wine) and sample evaluation by this protocol was done in duplicate obtaining a total of 62 observations. All data was acquired in controlled sensory laboratory conditions by means of the software TimeSens ${ }^{\odot}$ (www.timesens.com).

All TDS data is characterized by a sequentiality of dominant attributes which also have a given duration. For the purpose of clarity in the presentation of the proposed data analysis, an example of the type of data which can be obtained by panellist is shown in Fig. 2.

Table 1

Wine samples evaluated for data acquisition.

\begin{tabular}{lllll}
\hline Code & Type of grape & Type of wine & Wine region & Year \\
\hline V1 & Chardonnay & White, dry & Bourgogne, France & 2012 \\
V2 & Pinot Noir & Rosé, dry & Champagne, France & 2012 \\
V3 & Pinot Noir & Red & Bourgogne, France & 2012 \\
V4 & Gamay & Red & Beaujolais, France & 2014 \\
\hline
\end{tabular}




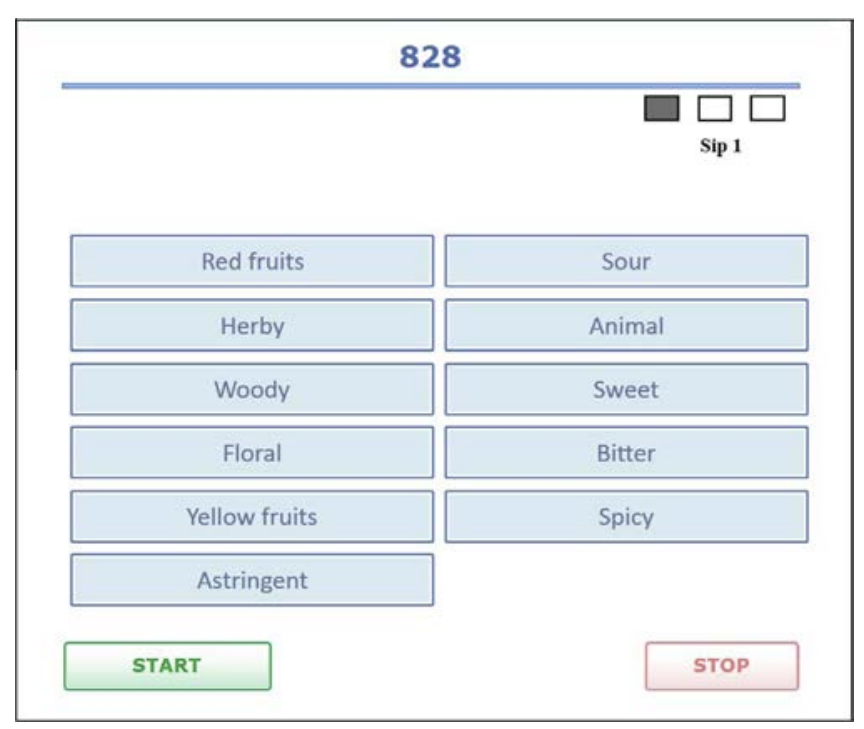

Fig. 1. Screen presented for sample evaluation. This was repeated three times to evaluate the three consecutive sips of a same sample.

\section{Representation of sequentiality: the bandplot and the bandplot by descriptor}

TDS data is usually represented by TDS curves (originally presented by Pineau et al. (2009)) in which dominance rate of each recorded attribute is plotted along time. The dominance rate (\%) of an attribute is calculated by dividing its number of citations at a given moment by the number of judges times the number of replications. All the obtained values are then compared to the significance level in order to differentiate those results that are due to chance to those which come from an actual agreement among assessors. This so called significance level is the minimum value the dominance rate should have to be considered as significantly higher than $P_{0}$ at the $\alpha \%$ level of risk. This is calculated using a confidence interval of a binomial proportion based on a normal approximation. Usually, TDS curves also present the lines corresponding to chance level and to significance level. If the attribute's curve is above the significance level, it is considered as dominant at that time point. If it is in-between the chance and the significance level, it could be considered as having a tendency towards dominance.

This is the most complete way of presenting TDS information showing for each attribute whether dominance is significant or not and also the dominance rate, which could be considered an index of panel agreement. Nonetheless, curves can have certain drawbacks. When working with complex products which might have several dominant attributes at a time, the visual inspection of curves and product comparison can become a cumbersome task. This is even more evident when working with multi-intake TDS where products and intakes might want to be compared at the same time. In Fig. 3A, TDS curves of three successive sips (time standardized between 0 and 1 , details on time standardization for curve representation will be given ahead in this section) of sample V1 (Table 1) are presented. It should be noted that all information below significance level has been shaded in order to partially eliminate visual noise. At the beginning of sip 1 , sweet, yellow fruits and sour were dominant. While yellow fruits continued to be dominant for the rest of the sip (with varying dominance rates), sour became dominant again at the end of the sip together with some astringency; in the middle of the sip the attribute floral was also dominant. A description with similar type of information could be done for sips 2 and 3. Nonetheless, it is hard to quickly follow the evolution of the different attributes along the three sips and to spot differences among sips at a glance. In short, curves show all the detailed information but they do not show us the global picture.

Monterymard, Visalli, and Schlich (2010) had proposed the TDS bandplot as an alternative to the TDS curves. For each product, the sequences of dominances were represented as time-bands of colored rectangles with lengths proportional to durations of dominance. The idea was to simplify the TDS curves interpretation by deciding on the best sequence of attribute dominances, keeping only the attribute with the highest dominance rate within an interval of time. Showing just one dominant attribute by time period was quite a reductionist representation and was soon abandoned by the authors in favor of a new one more in line with TDS curves, where several attributes can be dominant at the same time. This new bandplot - here represented in Fig. 3B - is a yes/no graph

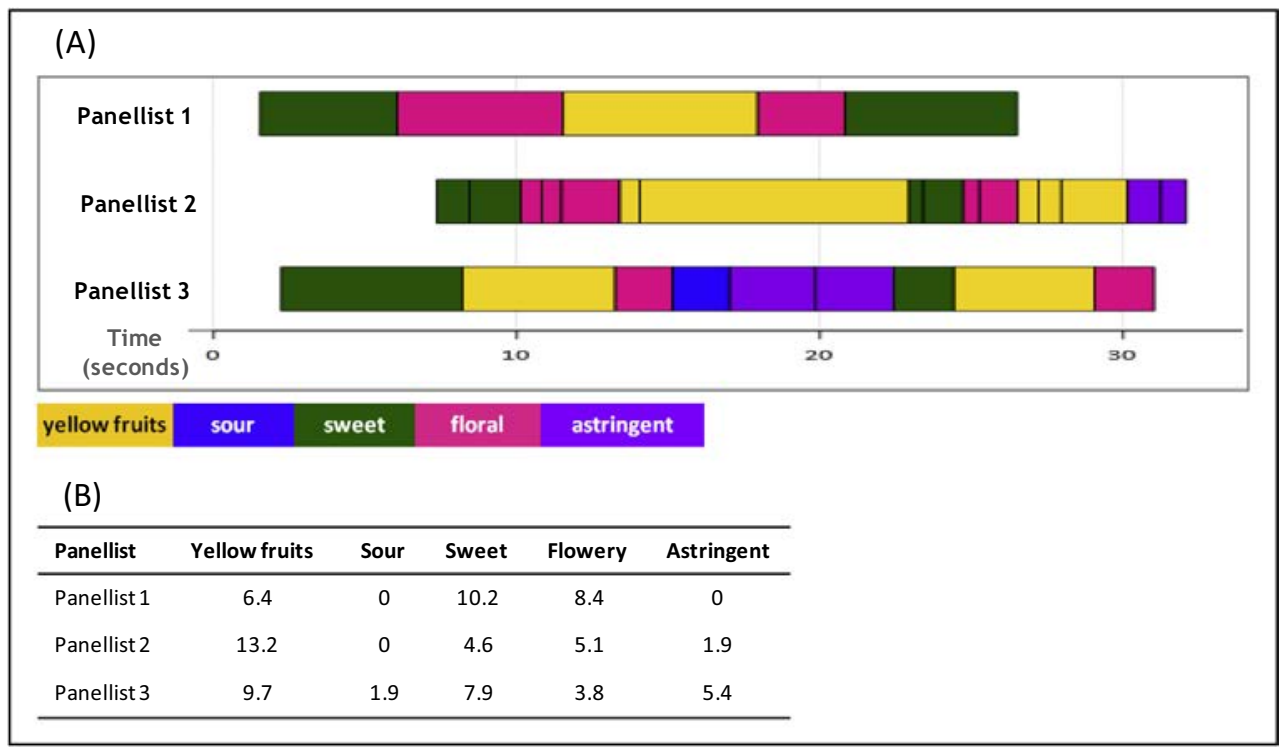

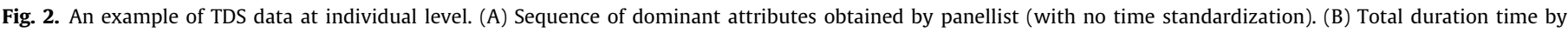
attribute and panellist. 


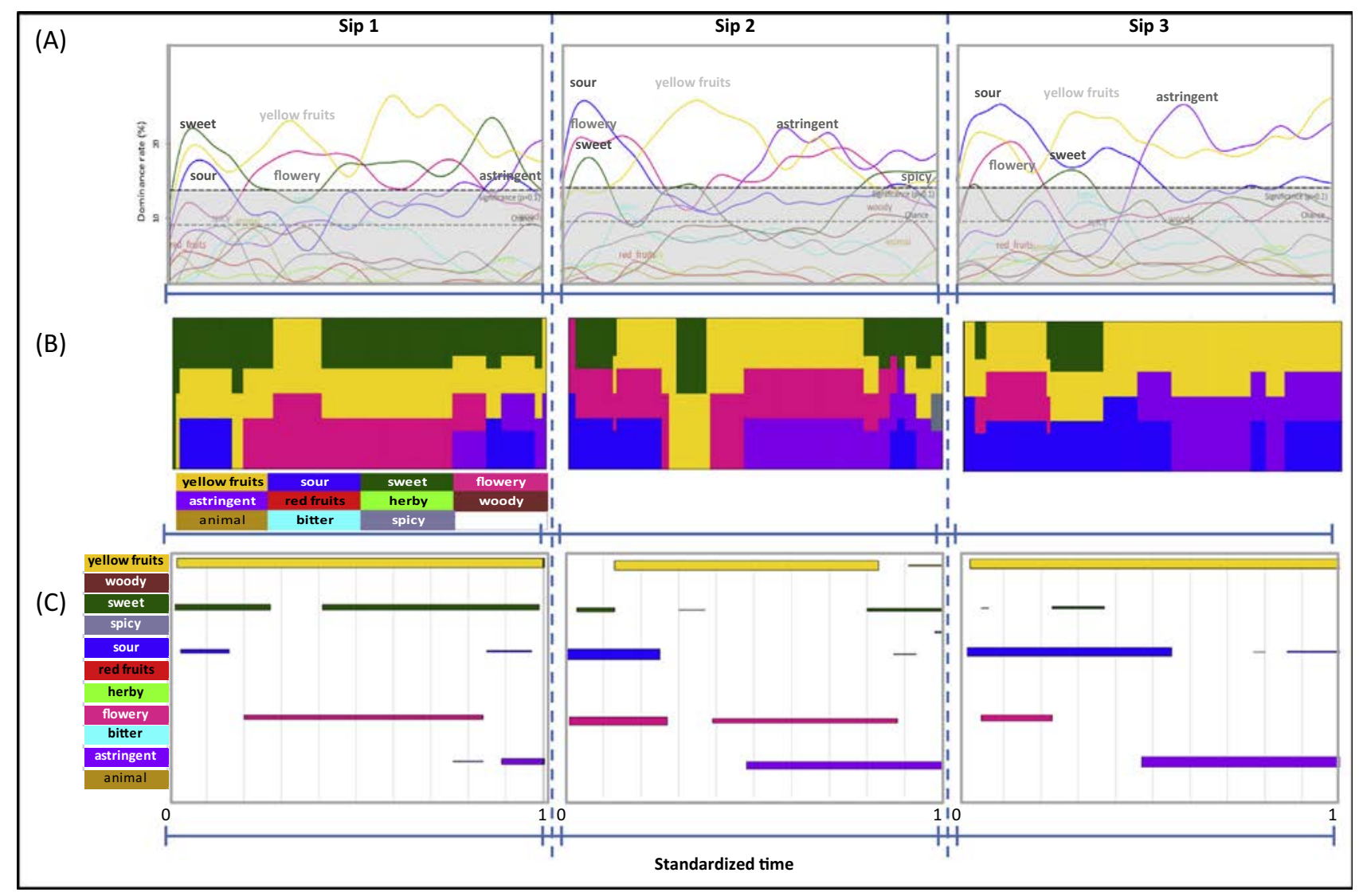

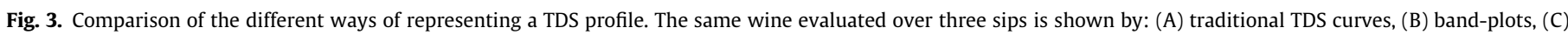
band-plots by attribute with height relative to dominance rate.

which shows all attributes above significant level without taking into account the dominance rate. All significant dominant attributes are represented by colored rectangles which are stacked at each moment being able to represent multiple dominances at a same time. The total height of the band (which should not be confused with a $y$-axis) is constant and the amount of colors at each moment depends on the number of dominant attributes at the same time, providing a characteristic "patchwork" effect. In this way, this representation minimizes the space used allowing the representation of several sips and/or products on a same page and therefore a better multiple product comparison. Moreover, global differences among sips (or products) can be spotted at a glance due to changes in colors: e.g. in Fig. 3B the amount of blue and violet is much more important in sip 3 than in sip 1, quickly seeing differences on sour and astringent. However; it can be difficult to follow the continuity of a dominant attribute along time (either between products or along intakes) and relative importance of attributes in terms of dominance rate is lost. For example, when looking at the representation of the first sip in Fig. 3B, in the second half of the sip, it could be thought that flowery, sweet and yellow fruits are equally dominant when in the curves (Fig. 3A) it can be seen that yellow fruits has a higher dominance rate than flowery.

To overcome this, another representation is proposed: bandplots by attribute; turning the plot into a two-dimension graph with the $x$-axis showing time and the $y$-axis showing the different descriptors (Fig. 3C). In this way, evolution of attributes along intakes can be easily followed, as opposed to the previously described bandplots (and curves). Bandplots by descriptor could be conceived with two different approaches: (i) as a yes/no graph were only significantly dominant attributes are presented and all attribute bars have an equal height; or (ii) including certain dominance rate information by making the bars' heights proportional to dominance rates giving an idea of the order of importance of attributes for the panel. This is calculated for each attribute as: mean dominance rate of the attribute at a given dominance period divided by the maximum dominance rate obtained (by sip, product or product $*$ sip, depending on the experimenters' preferences). So when looking again at the second half of the first sip, it can be observed that the bar for yellow fruits is higher than that of flowery (Fig. 3C), therefore showing that its dominance rate was bigger (as seen in Fig. 3A). It should be noticed that this shows only a proportion of dominance rates between attributes and not the actual dominance rate (\%) as in the curves. Finally, the evolution of each descriptor over sips is easily followed. In the case of the wine presented in Fig. 3C it can be observed that the dominance of sour and of astringent increased over sips while sweet decreases and yellow fruits stays almost constant and dominant along the three sips. In this way, this bandplot by attribute allows to quickly follow the evolution of dominance of each attribute while providing some information on panel agreement. This can be highly relevant in complex products were more than one attribute can be significantly dominant at a certain moment, at panel level. Additionally, the attributes available for panellists but which were not significant can be clearly spotted, e.g.: woody, red fruit, bitter, and animal never reached significance for the represented product while spicy was at the limit of significance (Fig. 3A, sip 2).

The proposed bandplots, as well as the traditional TDS curves, represent the evaluation of the whole panel. It is well known that mastication and swallowing behaviors change among individuals, so in order to be able to summarize their sensations at the beginning, the middle and the end of their evaluation, time is standardized. When the sequentiality of the product is of interest regardless 
of the total time duration of the product evaluation, standardization could be done between 0 (the first click) and 1 (the end of the evaluation). This has one drawback: the $X$-axis no longer represents real time but the evaluation period from first scoring to the end of the evaluation; so the time unit is lost. If differences in time of total product evaluation are of interest (e.g.: duration of product evaluation wants to be compared), then " $0-1$ " standardized times can be multiplied by the corresponding product's (or intake) mean duration in order to keep certain information on duration. In Fig. 3 curves were standardized between 0 and 1 . All these representations were done using the TimeSens ${ }^{\circledR}$ software.

\section{Statistical tests: ANOVA/MANOVA of dominance durations}

As already mentioned, duration of dominance is the other key information of TDS data. This is obtained at individual level by adding all the time periods during which the attribute was cited as dominant, regardless of the moment of perception (Fig. 2) (for the attributes which were cited, duration is 0 ). In this way, sequentiality (the following of one dominant sensation after the other) is lost, but statistical power is gained while keeping a temporal variable. Duration of dominance at individual and also panel level is not subjected to any pre-treatment as opposed to the univariate approaches for TDS data analysis which can be found in the literature (Dinnella, Masi, Naes, \& Monteleone, 2013; Hutchings, Foster, Grigor, et al., 2014; Hutchings, Foster, Hedderley, et al., 2014; Lepage et al., 2014).

Hutchings, Foster, Grigor, et al. (2014) summarized the time dimension of every raw standardized sequence into time intervals of the nearest $5 \%(5 \%, 10 \%, 15 \%$ until 100$)$. An active attribute was assigned ' 1 ', and an inactive attribute was assigned ' 0 ' at any point of the standardized sequence. A count was then undertaken of the number of time intervals which fitted into each of those four categories across all sets of replicates. The count in each category could then be converted into the percentage of sequence as each time interval represented 5\%. They referred to this value as the average dominance rate which they tested using a generalized Linear Mixed Model across the entire subject/product data set. The use of time intervals is an interesting approach when trying to compare sequentiality of sensations across subjects or products (Lepage et al., 2014) even if there is still not a clear rule of thumb as to the amount of periods which should be used. However, the idea of summarizing all the periods into a count and then express this as average dominance rate in order to carry out univariate analyses on total dominance seems like an over data manipulation.

This is why we propose to work directly with duration of dominance which also eliminates the dependency of data between periods. This quantitative value depends on subject, product and intakes, and can be analyzed with ANOVA or MANOVA models explaining differences among samples, intakes, or both. This approach is similar to that classically done on descriptive profile (Stone \& Sidel, 1993), but keeping in mind that the variable of interest is the duration time of a given sensation as dominant and not an intensity.
Since this comparison is presented in terms of duration of dominance, the total duration of the sip should be considered before getting into attribute analysis. As previously mentioned, for the data set of our example, panellists had no time limit for the TDS evaluation. Even though many published works on TDS description of food products have used a fixed time for sip or bite (Paulsen, Næs, Ueland, Rukke, \& Hersleth, 2013; Sokolowsky, Rosenberger, \& Fischer, 2015; Zorn et al., 2014), one of the aims of a dynamic approach could be to explore perception with a view closer to real consumption. Therefore imposing a time limit might be practical for data analysis but not the ideal way of obtaining sensory temporal information.

Taking this into account, all wine sips could have a different total duration, which could have a direct impact on the dominance duration of an attribute and this should be explored. Table 2 shows the mean and standard error of total sip duration for all four wines and sips of the present data set. As it can be observed, even if the standard error was quite high, the total duration was longer at every sip for wine V3 than for the other wines.

Looking at these results the experimenter could:

(i) Consider that differences in total duration were wine and sip related. Therefore their possible impact on attribute duration should be included in the data analysis. This is also in agreement with the fact that total time was not controlled in data acquisition to be closer to consuming conditions.

(ii) Try to remove differences in product durations by replacing actual duration of an attribute (in seconds) by its standardized duration.

Depending on the experimenters' hypothesis, both approaches could be valid. Given that in the present protocol data acquisition was done with no time limit, it was not within our interest to remove differences of product duration in the analysis. This is why a deeper analysis will be presented on non-standardized data, even if a brief description on standardized data will be later provided.

\subsection{ANOVA/MANOVA of non-standardized dominance durations}

Using dominance duration as the explanatory variable, multisip TDS data can be analyzed by an ANOVA (by attribute) according to the following mixed model:

$$
\begin{aligned}
\text { Duration }= & \text { Subject }+ \text { Product }+ \text { Sip }+ \text { Subject } * \text { Product }+ \text { Subject } \\
& * \text { Sip }+ \text { Product } * \text { Sip; }
\end{aligned}
$$

where Subject and the two interactions including it are considered as random factors and differences due to product, sip and the interaction of both, are tested by the statistics:

F-product $=$ MS-product/MS-product $*$ subject.

F-sip $=$ MS-sip/MS-subject $*$ sip.

F-product $* \operatorname{sip}=$ MS-product $* \operatorname{sip} /$ MS-error.

The same model can be extended in a multidimensional way (considering all attributes at the same time) with a MANOVA in

Table 2

\begin{tabular}{|c|c|c|c|c|c|}
\hline & ${ }^{\mathrm{a}} \mathrm{F}$-value & V1 & V2 & V3 & V4 \\
\hline Sip 1 & $9.6^{* * *}$ & $30.29 \pm 15.15(b)$ & $28.87 \pm 13.16(b)$ & $35.22 \pm 18.31(a)$ & $29.40 \pm 16.95$ (b) \\
\hline Sip 2 & $8.98^{* * *}$ & $27.65 \pm 14.04(b)$ & $26.64 \pm 12.48(\mathrm{~b})$ & $31.66 \pm 14.08(a)$ & $28.37 \pm 15.54(b)$ \\
\hline Sip 3 & $25.81^{* * *}$ & $27.48 \pm 15.51(\mathrm{bc})$ & $25.06 \pm 13.09(\mathrm{c})$ & $35.63 \pm 15.94(a)$ & $28.29 \pm 17.15(b)$ \\
\hline
\end{tabular}

Mean and standard error of total sip duration.

$p<0.001$; different letters represent differences among wines for each sip according to a LSD test.

a $F$-test of the main effect in the two-way ANOVA model wine + subject by sip. 
order to get a global view of differences among products and sips. Table 3 presents the ANOVA/MANOVA results obtained with the present data. The MANOVA F was obtained according to the Hotelling-Lawley statistic (Peltier, Visalli, \& Schlich, 2015a).

As when analyzing results from sensory profiling, the first thing that can be observed in Table 3 is that the interaction product $*$ sip was significant for the attribute astringency and also slightly for the overall MANOVA test. This means that the evolution of dominance duration along sips for that attribute was not the same for all products. As when analyzing results from a quantitative profile, when the interaction is significant, results concerning F-product or Fsip should be interpreted with caution, particularly for this descriptor.

Other than for astringency, the F-product was significant for 8 attributes $(p<0.05)$, meaning that their dominance duration was different among products, when evaluating all sips at the same time. As in a quantitative profile, products can be regrouped according to the attribute's dominance duration with a post hoc test (e.g. Tukey's HSD). So, for example, it was found that sample V1 was different from the rest having a longer duration of yellow fruits as a dominant attribute; while sample V3 was the one with the longest duration of woody. Moreover the F-product value of the MANOVA (Table 3) shows that samples were different at a multidimensional level.

Table 3 also shows differences between sips, when analyzing all products at the same time (F-sip). There were differences between sips (all products combined) for the attributes yellow fruits $(p<0.1)$, astringent $(p<0.001)$, sweet $(p<0.001)$, woody $(p<0.01)$ and flowery $(p<0.01)$. In the case of consecutive intakes, additionally to the post hoc test, linear trends with sequential contrasts can be tested. This can be done in different ways: (i) comparing each sip vs. the previous one; (ii) comparing each sip vs. the first one, which could be a less restrictive approach. The choice could vary according to the number of intakes and the aim of the experiment. In the present example all sips were tested against the first one. $E$. g. sweet was significantly different in sip 1 from sips 2 and 3 due to a decrease in dominance duration time along sips (indicated by a minus symbol). The same could be observed for the aromas woody and flowery. In the case of yellow fruits, for which change was slightly significant, there was no clear pattern of increase/decrease along intakes. As already stated, this shows the evolution of the duration of dominance of attributes over intakes for all products at the same time.

Given that a significant F-product $*$ sip was found for astringent the evolution of the product along sips should be evaluated by an ANOVA by product, according to the mixed model:

\section{Duration $=$ Subject + Sip}

This model can also be extended to a MANOVA to see if there is a difference among sips. This can be of special interest, for example, when evaluating one product over several intakes to assess the whole portion. Results of this test done on V2 are presented in Table 4. It could be observed that the dominance durations of three attributes changed: astringent, woody and flowery; having also a significant F-value in MANOVA at a global level.

Table 4

ANOVA/MANOVA results for the duration of dominance of each attribute (in seconds) for the wine V2 over the different sips.

\begin{tabular}{|c|c|c|c|c|}
\hline V2 & F-Sip & Sip 1 & Sip 2 & Sip 3 \\
\hline Flowery & $6.46^{* *}(-)$ & $\begin{array}{l}4.61 \pm 0.56 \\
\text { (b) }\end{array}$ & $\begin{array}{l}2.45 \pm 0.56 \\
\text { (a) }\end{array}$ & $1.93 \pm 0.56(\mathrm{a})$ \\
\hline Astringent & $4.26^{*}(+)$ & $\begin{array}{l}4.05 \pm 0.64 \\
\text { (a) }\end{array}$ & $\begin{array}{l}6.70 \pm 0.64 \\
\text { (b) }\end{array}$ & $\begin{array}{l}5.21 \pm 0.64 \\
(\mathrm{ab})\end{array}$ \\
\hline Sweet & $3.73^{*}(-)$ & $\begin{array}{l}2.34 \pm 0.35 \\
\text { (b) }\end{array}$ & $\begin{array}{l}1.06 \pm 0.35 \\
\text { (a) }\end{array}$ & $\begin{array}{l}1.33 \pm 0.35 \\
(\mathrm{ab})\end{array}$ \\
\hline Sour & $3.41^{*}(-)$ & $\begin{array}{l}6.40 \pm 0.60 \\
\text { (b) }\end{array}$ & $\begin{array}{l}4.18 \pm 0.60 \\
\text { (a) }\end{array}$ & $\begin{array}{l}5.29 \pm 0.60 \\
(\mathrm{ab})\end{array}$ \\
\hline Animal & 2.35 & $1.02 \pm 0.39$ & $1.1 \pm 0.39$ & $0.55 \pm 0.39$ \\
\hline Bitter & 1.32 & $2.53 \pm 0.58$ & $3.19 \pm 0.58$ & $3.87 \pm 0.58$ \\
\hline Spicy & 1.28 & $1.38 \pm 0.34$ & $2.09 \pm 0.34$ & $1.49 \pm 0.34$ \\
\hline Herby & 0.77 & $0.9 \pm 0.44$ & $1.2 \pm 0.44$ & $0.62 \pm 0.44$ \\
\hline Yellow_fruits & 0.71 & $1.52 \pm 0.25$ & $1.25 \pm 0.25$ & $1.10 \pm 0.25$ \\
\hline Woody & 0.54 & $2.32 \pm 0.40$ & $1.75 \pm 0.40$ & $1.96 \pm 0.40$ \\
\hline Red_fruits & 0.05 & $1.80 \pm 0.27$ & $1.68 \pm 0.27$ & $1.72 \pm 0.27$ \\
\hline $\begin{array}{l}\text { Overall } \\
\text { (MANOVA) }\end{array}$ & $3.06^{* * *}$ & & & \\
\hline
\end{tabular}

Significance levels: (.) $10 \%,{ }^{*} 5 \%,{ }^{* *} 1 \%,{ }^{* * *} 0.1 \%$. Different letters identify product groups according to Tukey HSD. Symbols $+/$ - indicate an increasing or decreasing linear trend.

Table 3

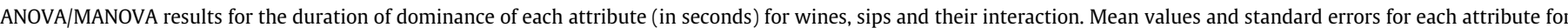
each product/sip are provided.

\begin{tabular}{|c|c|c|c|c|c|c|c|c|c|c|}
\hline & F-prod & V1 & V2 & V3 & V4 & F-sip & Sip 1 & Sip 2 & Sip 3 & $\begin{array}{l}\mathrm{F}- \\
\operatorname{prod} * \operatorname{sip}\end{array}$ \\
\hline Yellow_fruits & $19.71^{* * *}$ & $\begin{array}{l}5.36 \pm 0.54 \\
\text { (b) }\end{array}$ & $\begin{array}{l}1.29 \pm 0.54 \\
\text { (a) }\end{array}$ & $\begin{array}{l}0.35 \pm 0.54 \\
\text { (a) }\end{array}$ & $\begin{array}{l}1.12 \pm 0.54 \\
\text { (a) }\end{array}$ & $2.37().(-)$ & $\begin{array}{l}2.39 \pm 0.35 \\
\text { (b) }\end{array}$ & $\begin{array}{l}1.75 \pm 0.35 \\
\text { (a) }\end{array}$ & $\begin{array}{l}1.96 \pm 0.35 \\
(\mathrm{ab})\end{array}$ & 1.16 \\
\hline Astringent & $12.64^{* * *}$ & $\begin{array}{l}4.29 \pm 0.81 \\
\text { (a) }\end{array}$ & $\begin{array}{l}5.32 \pm 0.81 \\
\text { (a) }\end{array}$ & $\begin{array}{l}8.72 \pm 0.81 \\
\text { (b) }\end{array}$ & $\begin{array}{l}5.91 \pm 0.81 \\
\text { (a) }\end{array}$ & $16.62^{* * *}(+)$ & $\begin{array}{l}4.61 \pm 0.73 \\
\text { (a) }\end{array}$ & $\begin{array}{l}6.03 \pm 0.73 \\
\text { (b) }\end{array}$ & $7.55 \pm 0.73(\mathrm{c})$ & $11.59^{* * *}$ \\
\hline Sweet & $9.84^{* * *}$ & $\begin{array}{l}3.58 \pm 0.45 \\
\text { (b) }\end{array}$ & $\begin{array}{l}1.58 \pm 0.45 \\
\text { (a) }\end{array}$ & $\begin{array}{l}0.53 \pm 0.45 \\
\text { (a) }\end{array}$ & $\begin{array}{l}1.56 \pm 0.45 \\
\text { (a) }\end{array}$ & $10.399^{* * *}(-)$ & $2.6 \pm 0.33(b)$ & $\begin{array}{l}1.53 \pm 0.33 \\
\text { (a) }\end{array}$ & $\begin{array}{l}1.32 \pm 0.33 \\
\text { (a) }\end{array}$ & 1.37 \\
\hline Red_fruits & $9.81^{* * * *}$ & $\begin{array}{l}0.55 \pm 0.67 \\
\text { (a) }\end{array}$ & $\begin{array}{l}1.73 \pm 0.67 \\
\text { (a) }\end{array}$ & $\begin{array}{l}3.42 \pm 0.67 \\
\text { (b) }\end{array}$ & $\begin{array}{l}3.92 \pm 0.67 \\
\text { (b) }\end{array}$ & 0.51 & $2.56 \pm 0.54$ & $2.34 \pm 0.54$ & $2.32 \pm 0.54$ & 0.97 \\
\hline Woody & 8.61 $^{* * *}$ & $\begin{array}{l}1.96 \pm 0.61 \\
\text { (a) }\end{array}$ & $\begin{array}{l}2.01 \pm 0.61 \\
\text { (a) }\end{array}$ & $\begin{array}{l}5.57 \pm 0.61 \\
\text { (b) }\end{array}$ & $\begin{array}{l}2.35 \pm 0.61 \\
\text { (a) }\end{array}$ & $\mathbf{5 . 9 0}{ }^{* *}(-)$ & $\begin{array}{l}3.47 \pm 0.39 \\
\text { (b) }\end{array}$ & $\begin{array}{l}3.16 \pm 0.39 \\
\text { (b) }\end{array}$ & $\begin{array}{l}2.28 \pm 0.39 \\
\text { (a) }\end{array}$ & 0.97 \\
\hline Flowery & $\mathbf{8 . 0 0}^{* * * *}$ & $\begin{array}{l}4.13 \pm 0.60 \\
\text { (c) }\end{array}$ & $\begin{array}{l}3.00 \pm 0.6 \\
\text { (bc) }\end{array}$ & $1.01 \pm 0.60(a)$ & $\begin{array}{l}1.76 \pm 0.6 \\
(\mathrm{ab})\end{array}$ & $6.34^{* *}(-)$ & $\begin{array}{l}3.17 \pm 0.48 \\
\text { (b) }\end{array}$ & $\begin{array}{l}2.32 \pm 0.48 \\
\text { (a) }\end{array}$ & $\begin{array}{l}1.94 \pm 0.48 \\
\text { (a) }\end{array}$ & 1.47 \\
\hline Bitter & $7.94^{* * *}$ & $\begin{array}{l}1.64 \pm 0.53 \\
\text { (a) }\end{array}$ & $\begin{array}{l}3.20 \pm 0.53 \\
\text { (b) }\end{array}$ & $\begin{array}{l}4.32 \pm 0.53 \\
\text { (b) }\end{array}$ & $\begin{array}{l}3.40 \pm 0.53 \\
\text { (b) }\end{array}$ & 0.91 & $2.85 \pm 0.47$ & $3.19 \pm 0.47$ & $3.37 \pm 0.47$ & 0.57 \\
\hline Spicy & $4.25^{* *}$ & $\begin{array}{l}1.59 \pm 0.47 \\
\text { (a) }\end{array}$ & $\begin{array}{l}1.65 \pm 0.47 \\
\text { (a) }\end{array}$ & $\begin{array}{l}3.33 \pm 0.47 \\
\text { (b) }\end{array}$ & $\begin{array}{l}2.49 \pm 0.47 \\
(\mathrm{ab})\end{array}$ & 1.40 & $2.4 \pm 0.37$ & $2.42 \pm 0.37$ & $1.97 \pm 0.37$ & 1.16 \\
\hline Animal & $3.66^{*}$ & $\begin{array}{l}0.67 \pm 0.36 \\
\text { (a) }\end{array}$ & $\begin{array}{l}2.01 \pm 0.36 \\
\text { (b) }\end{array}$ & $\begin{array}{l}0.89 \pm 0.36 \\
(\mathrm{ab})\end{array}$ & $\begin{array}{l}0.96 \pm 0.36 \\
(\mathrm{ab})\end{array}$ & 0.97 & $1.22 \pm 0.26$ & $1.19 \pm 0.26$ & $1.00 \pm 0.26$ & 1.19 \\
\hline Sour & 1.54 & $3.88 \pm 0.70$ & $5.29 \pm 0.70$ & $3.78 \pm 0.70$ & $4.41 \pm 0.70$ & 1.72 & $4.75 \pm 0.59$ & $3.81 \pm 0.59$ & $4.45 \pm 0.59$ & 0.71 \\
\hline Herby & 1.08 & $1.10 \pm 0.30$ & $1.12 \pm 0.30$ & $0.90 \pm 0.30$ & $0.53 \pm 0.30$ & 0.13 & $0.94 \pm 0.24$ & $0.85 \pm 0.24$ & $0.96 \pm 0.24$ & 1.32 \\
\hline $\begin{array}{l}\text { Overall } \\
\quad \text { (MANOVA) }\end{array}$ & $7.05^{* * *}$ & & & & & $4.43^{* * *}$ & & & & $2.09^{* * *}$ \\
\hline
\end{tabular}

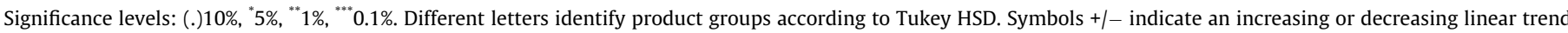
along sips. Significant F-values have been highlighted in bold. 
In the same way, differences between products at a particular sip could be tested performing an ANOVA by sip, according to the mixed model: Duration $=$ Subject + Product, which could also be extended by a MANOVA to see differences at a multidimensional level. In all cases, Subject should be treated as a random factor.

\subsection{ANOVA/MANOVA of standardized dominance durations}

As previously stated, depending on the interest of the experimenter, total duration of intakes can be standardized turning dominance duration of each attribute into a proportion of the total duration. Time can also be de facto considered as standardized when the time for each sip is fixed by the experimenter beforehand.

Table 5 shows results done on the present data set after standardization, where duration of each attribute is expressed as a percentage of the total duration. In the present case, obtained results were not that different; except for the attribute sour, which became slightly significant at product level and spicy, which had a lower significance at product level but higher in order to discriminate among sips.

Moreover, data standardization has an added value: it easily shows the contribution of each attribute to the complete evaluation. This might be harder to see when working with nonstandardized. However, it should be taken into consideration whether data is standardized or not since it prevents explaining differences based on attributes that have such a short duration that might not represent the product. For example, in Table 2 it was pointed out that the duration of the attribute herby was not different among wines. For this same attribute, Table 5 shows that its duration was equal or shorter than $3 \%$ of the total duration of the sip. In this way, it can be concluded that this attribute was not relevant for the description of these wines. This could also be the case of animal, which lasted longer in V3 but represented only $7 \%$ of total duration (Tables 3 and 5). So even if the duration of animal was significantly different among products, it was not an important attribute in the temporality of the sip.

The downside of data standardization is that sometimes MANOVA cannot be computed because of co-linearities. This also prevents its multi-dimensional representation.

\section{General overview and representation: Canonical Variate Analysis}

Canonical Variate Analysis (CVA) is a mapping method which allows the results of a MANOVA to be plotted on a map (Peltier, Visalli, \& Schlich, 2015b). In sensory profiling, CVA is often used to quantify product discrimination based on the F-product of the two-way MANOVA model: Intensity = Product + Subject + Interactions (Peltier et al., 2015a). With TDS data, intensity scores are replaced with duration of dominance and taking into account results of the global model (shown in Section 4), several maps could be of interest. It should be noted that this approach is different from a trajectory map which maps the succession of perceived events (Lenfant et al., 2009) without including a statistical test and does not aim to replace it but to complement the information showing product differences in terms of duration of dominance regardless of the sequentiality.

Table 3 showed that there were differences among products in terms of duration of dominance on almost all attributes with a significant F-product in the MANOVA. These differences are even better represented in Fig. 4a where the four wines were plotted considering an average of their three intakes. This approach had been introduced by Thomas et al. (2015), however in this work authors had only one intake by product. When having more than one intake, these can either be represented by the average of all intakes (Fig. 4a) or they can be projected on the same map in order to also have a representation of their evolution within each product (Fig. 4b). These figures show that V1 was the one with the longest duration of dominance for the attributes yellow fruits, sweet and flowery. On the other hand, V3 was the one with a longest duration of astringency, woody, animal, herby and spicy. Finally, wines V2 and V4 were the most similar ones in terms of duration of dominance of the different descriptors being both described by the persistence of bitter, red fruits and sour. In all cases, the confidence ellipses allow to represent the distribution of subjects around the mean, where the mean point has $90 \%$ probability to be (Peltier et al., 2015a). Furthermore, in the CVA context, a maximum likelihood test allows to assess the number of significant discriminant dimensions (Peltier et al., 2015a) (e.g.: NDIM = 2, Fig. 4). It should be noted that this representation enhances differences among samples in terms of duration of dominance, however when analyzing results, the contribution of each attribute to the total duration of the evaluation should be taken into account.

In relation to sip evolution, it could also be of interest to plot the evolution of each sip taking into account all products at the same time (second part of Table 3). This could be the case if we wanted to know if the duration of dominance of gustative descriptors increase along sips while aromatic decrease, regardless of the product evaluated. In the same way as for product, this can be plotted in a CVA showing multivariate evolution (Fig. 5).

Finally, this also allows mapping the evolution of one product over several intakes showing perceived changes along consumption $($ Duration $=\mathrm{Sip}+$ Subject). This is represented in Fig. 6 for product V2 (the corresponding ANOVA/MANOVA was presented

Table 5

ANOVA/MANOVA results for proportion (\%) of dominant attribute duration (data after standardization) for wines, sips and their interaction and their standard error.

\begin{tabular}{|c|c|c|c|c|c|c|c|c|c|c|}
\hline & F-prod & V1 & V2 & V3 & V4 & F-sip & Sip 1 & Sip 2 & Sip 3 & F-prod $*$ rep \\
\hline Yellow_fruits & 22.51 ${ }^{* * *}$ & $4 \pm 2(a)$ & $1 \pm 2(a)$ & $7 \pm 2(a)$ & $20 \pm 2(b)$ & 0.33 & $8 \pm 1$ & $8 \pm 1$ & $8 \pm 1$ & 0.31 \\
\hline Sweet & $13.11^{* * *}$ & $5 \pm 2(a b)$ & $2 \pm 2(a)$ & $8 \pm 2(b)$ & $14 \pm 2(c)$ & $6.59^{* *}(-)$ & $9 \pm 1(b)$ & $6 \pm 1(a)$ & $6 \pm 1(a)$ & 0.92 \\
\hline Red_fruits & $10.17^{* * *}$ & $13 \pm 2(c)$ & $8 \pm 2(b c)$ & $6 \pm 2(a b)$ & $2 \pm 2(a)$ & 0.39 & $8 \pm 1$ & $7 \pm 1$ & $7 \pm 1$ & 0.72 \\
\hline Flowery & $9.66^{* * *}$ & $5 \pm 2(a)$ & $3 \pm 2(a)$ & $12 \pm 2(b)$ & $14 \pm 2(b)$ & $4.9^{* *}(-)$ & $10 \pm 1(b)$ & $9 \pm 1(a b)$ & $7 \pm 1(a)$ & 1.06 \\
\hline Astringent & $\mathbf{7 . 8 9}^{* * * *}$ & $22 \pm 2(b c)$ & $25 \pm 2(c)$ & $18 \pm 2(a b)$ & $14 \pm 2(a)$ & $18.33^{* * *}(+)$ & $15 \pm 2(a)$ & $20 \pm 2(b)$ & $24 \pm 2(c)$ & $5.62^{* * *}$ \\
\hline Bitter & $6.77^{* * *}$ & $15 \pm 2(b)$ & $15 \pm 2(b)$ & $13 \pm 2(b)$ & $6 \pm 2(a)$ & 2.02 & $11 \pm 2$ & $13 \pm 2$ & $13 \pm 2$ & 1.24 \\
\hline Woody & $5.31^{* *}$ & $8 \pm 2(a)$ & $15 \pm 2(b)$ & $8 \pm 2(a)$ & $5 \pm 2(a)$ & $6.22^{* *}(-)$ & $10 \pm 1(b)$ & $10 \pm 1(b)$ & $7 \pm 1(a)$ & 1.77 \\
\hline Animal & $3.67^{*}$ & $2 \pm 1(a)$ & $7 \pm 1(b)$ & $3 \pm 1(a b)$ & $3 \pm 1(a b)$ & 0.98 & $4 \pm 1$ & $4 \pm 1$ & $3 \pm 1$ & 0.63 \\
\hline Sour & $2.46()$. & $15 \pm 2$ & $11 \pm 2$ & $19 \pm 2$ & $15 \pm 2$ & 1.97 & $15 \pm 2$ & $14 \pm 2$ & $16 \pm 2$ & 1.76 \\
\hline Spicy & $2.24()$. & $8 \pm 1$ & $9 \pm 1$ & $5 \pm 1$ & $5 \pm 1$ & 2.93(.) & $7 \pm 1$ & $8 \pm 1$ & $6 \pm 1$ & 1.5 \\
\hline Herby & 0.38 & $3 \pm 1$ & $3 \pm 1$ & $3 \pm 1$ & $2 \pm 1$ & 0.23 & $3 \pm 1$ & $3 \pm 1$ & $3 \pm 1$ & 1.53 \\
\hline Overall (MANOVA) & $4.29^{* * *}$ & & & & & $4.50^{* * *}$ & & & & $1.43()$. \\
\hline
\end{tabular}

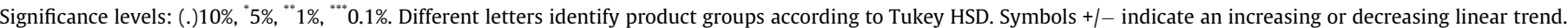
Significant F-values have been highlighted in bold. 


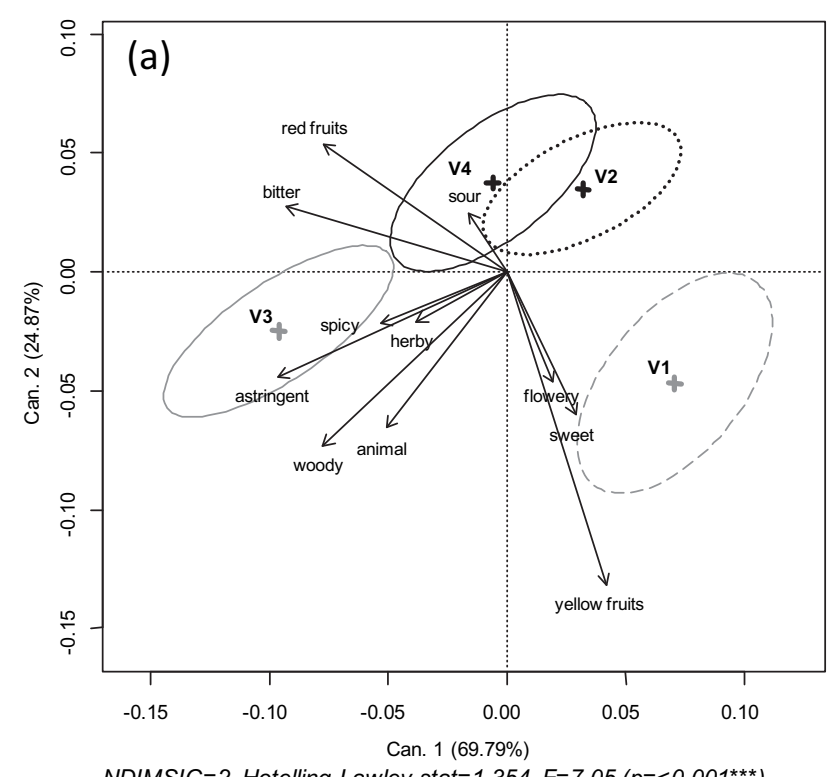

NDIMSIG=2, Hotelling Lawley stat=1.354, F=7.05 $\left(p=<0.001^{* * *}\right)$

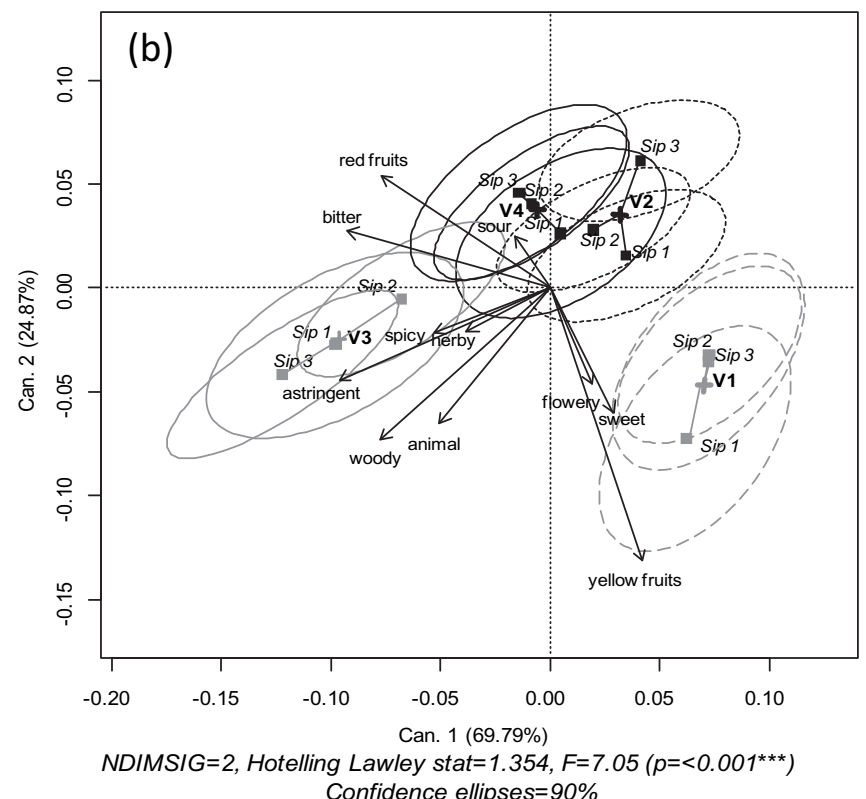

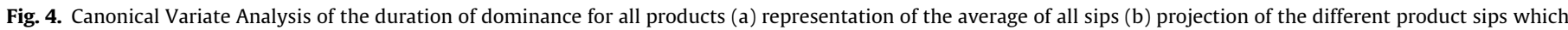
allows also to see the evolution of the different products among intakes.

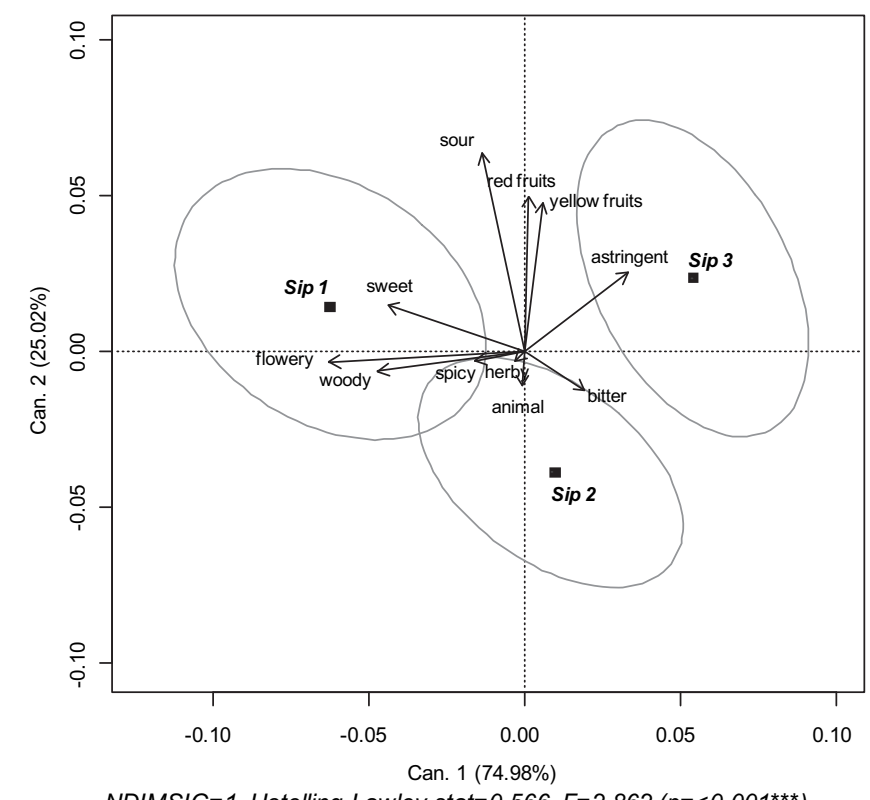

NDIMSIG=1, Hotelling Lawley stat=0.566, $F=2.862\left(p=<0.001^{\star * *}\right)$

Fig. 5. Canonical Variate Analysis of the duration of dominance for the different sips taking all products into account at the same time.

in Table 3). For this wine it could be observed that there is a difference in terms of duration of dominance between the sips. This can be of particular interest when looking at the evolution of a single product over the consumption of a whole portion.

As stated by Peltier et al. (2015a), one of the advantages of CVA is that it relies on a statistical model which allows also multidimensional tests of differences between products. Interpreting multidimensional differences with these tests other than visual inspection of ellipses avoids jumping to wrong conclusions. So when looking at Fig. 6 we would think that there is no global difference in terms of duration of dominance between sips 2 and 3 . Nonetheless, when looking at the results of the pairwise product

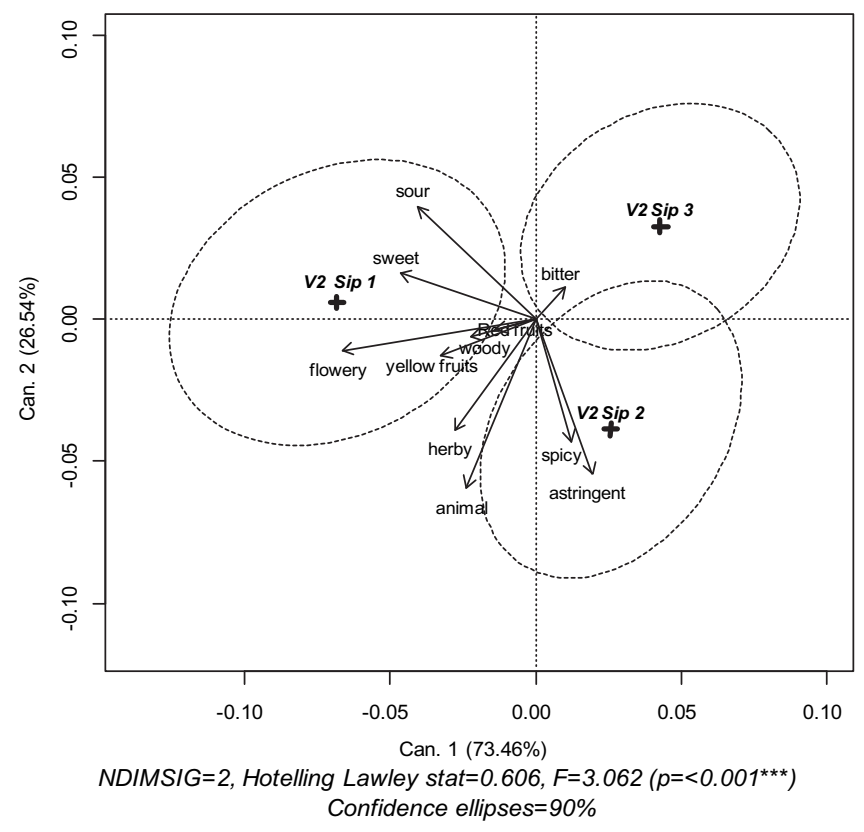

Fig. 6. Canonical Variate Analysis of the duration of dominance for product V2 over sips.

Table 6

CVA hotelling table, $p$-values for the different paired comparisons.

\begin{tabular}{llll}
\hline & V2 $-\operatorname{sip} 1$ & V2 $-\operatorname{sip} 2$ & V2 - sip 3 \\
\hline V2 - sip 1 & 1 & 0.003 & 0.008 \\
V2 - sip 2 & 0.003 & 1 & 0.085 \\
V2 - sip 3 & 0.008 & 0.085 & 1 \\
\hline
\end{tabular}

$p \leqslant 0.05^{*}$ product/sip differences.

differences of the Hotteling comparison (Table 6), it can be observed that if a $10 \%$ risk is considered, the three sips were significantly different. 


\section{Conclusions}

The purpose of the present paper was to present a new way of representing and analyzing TDS data aiming towards an optimization of statistical comparison, particularly when dealing with multiple intakes.

As for the representation of sequentiality, TDS curves are the graphs which give the most information, but this same richness is what makes it difficult to compare them over intakes or products and to get a global overview. For this purpose we propose simplified representations like the bandplot by descriptor which easily allows following the evolution of a descriptor along time and intakes while dominance rate is still somewhat represented by the bars' height.

Working with total duration can provide rich information while avoiding data pre-treatment and without relying on visual inspection or a priori determination of time periods. All these factors are very important when the amount of samples and intakes increase, which is to be expected when evaluating several products all along consumption of a whole portion, which is the new direction for the use of TDS. Using the total duration, a time related measurement is kept while using simple and quick tools currently applied in sensory profiling. Outputs can be summarized into classical ANOVA tables or even better, mapped while being statistically tested by a CVA revealing global differences of samples, intakes or even better, several intakes of different products in only one figure; always keeping in mind that we are comparing dominance durations and not intensities. This does not attempt to replace data analysis focused on sequentiality but to complement them in order to maximize the exploitation of this temporal method with statistical tools already well used in the sensory science world.

\section{Acknowledgement}

Mara V. Galmarini has received the support of the EU in the framework of the Marie-Curie FP7 COFUND People Programme, through the award of an AgreenSkills fellowship under grant agreement $n^{\circ} 267196$.

Authors would also like to thank Dr. Caroline Peltier and Arnaud Thomas for their advice and inputs on the subject.

\section{References}

Brachet, S., Galmarini, M., Chatelet, B., Loiseau, A.-L., Cordelle, S., Lempereur, V., et al. (2014). Evaluation de la Dominance Temporelle des Sensations de vins rouges de Bourgogne et du Beaujolais par un panel d'experts et de consommateurs. In 37th World congress of vine and wine and 12th general assembly of the OIV. EDP Sciences. 06006.

Bruzzone, F., Ares, G., \& Giménez, A. (2013). Temporal aspects of yoghurt texture perception. International Dairy Journal, 29, 124-134.

Cadena, R. S., Vidal, L., Ares, G., \& Varela, P. (2014). Dynamic sensory descriptive methodologies. Time-intensity and temporal dominance of sensations. In P. Varela \& G. Ares (Eds.), Novel techniques in sensory characterization and consumer profiling. CRC Press.

Castura, J. C., \& Li, M. (2016). Using TDS dyads and other dominance sequences to characterize products and investigate liking changes. Food Quality and Preference, 47(Part A), 109-121.
Devezeaux De Lavergne, M., Van Delft, M., Van De Velde, F., Van Boekel, M. A. J. S., \& Stieger, M. (2015). Dynamic texture perception and oral processing of semisolid food gels: Part 1: Comparison between QDA, progressive profiling and TDS. Food Hydrocolloids, 43, 207-217.

Di Monaco, R., Su, C., Masi, P., \& Cavella, S. (2014). Temporal dominance of sensations: A review. Trends in Food Science \& Technology, 38, 104-112.

Dinnella, C., Masi, C., Naes, T., \& Monteleone, E. (2013). A new approach in TDS data analysis: A case study on sweetened coffee. Food Quality and Preference, 30 , 33-46.

Hutchings, S. C., Foster, K. D., Grigor, J. M. V., Bronlund, J. E., \& Morgenstern, M. P. (2014). Temporal dominance of sensations: A comparison between younger and older subjects for the perception of food texture. Food Quality and Preference, 31, 106-115.

Hutchings, S. C., Foster, K. D., Hedderley, D. I., \& Morgenstern, M. P. (2014). Differences between age groups in the use of the temporal dominance of sensations technique across a range of food textures. Journal of Texture Studies, 45, 206-219.

Lenfant, F., Loret, C., Pineau, N., Hartmann, C., \& Martin, N. (2009). Perception of oral food breakdown. The concept of sensory trajectory. Appetite, 52, 659-667.

Lepage, M., Neville, T., Rytz, A., Schlich, P., Martin, N., \& Pineau, N. (2014). Panel performance for temporal dominance of sensations. Food Quality and Preference, 38, 24-29.

Marcano, J., Varela, P., Cunha, L. M., \& Fiszman, S. (2015). Relating dynamic perception of reformulated cheese pies to consumers' expectations of satiating ability. Food Research International, 78, 369-377.

Meyners, M. \& Pineau, N. (2010). Statistical inference for temporal dominance of sensations data using randomization tests. Food Quality and Preference, 21, 805-814.

Monterymard, C., Visalli, M., \& Schlich, P. (2010). The TDS-band plot: A new graphical tool for temporal dominance of sensations data. In 2nd conference of the society of sensory professionals (pp. 27-29).

Paulsen, M. T., Næs, T., Ueland, Ø., Rukke, E.-O., \& Hersleth, M. (2013). Preference mapping of salmon-sauce combinations: The influence of temporal properties. Food Quality and Preference, 27, 120-127.

Peltier, C., Visalli, M., \& Schlich, P. (2015a). Canonical variate analysis of sensory profiling data. Journal of Sensory Studies, 30, 316-328.

Peltier, C., Visalli, M., \& Schlich, P. (2015b). Comparison of canonical variate analysis and principal component analysis on 422 descriptive sensory studies. Food Quality and Preference, 40(Part B), 326-333.

Pineau, N., \& Schlich, P. (2014). Temporal dominance of sensations (TDS) as a sensory profiling technique. Rapid sensory profiling techniques: Applications in new product development and consumer research, 269.

Pineau, N., Cordelle, S., \& Schlich, P. (2003). Temporal dominance of sensations: A new technique to record several sensory attributes simultaneously over time. Journées de Statistique. Lyon, France.

Pineau, N., Schlich, P., Cordelle, S., Mathonnière, C., Issanchou, S., Imbert, A., et al. (2009). Temporal dominance of sensations: Construction of the TDS curves and comparison with time-intensity. Food Quality and Preference, 20, 450-455.

Rodrigues, J. F., Condino, J. P. F., Pinheiro, A. C. M., \& Nunes, C. A. (2016). Temporal dominance of sensations of chocolate bars with different Cocoa contents: A multivariate approach to assess Tds profiles. Food Quality and Preference, 47 (A), 6 .

Schlich, P. (2013). TDS with untrained consumers in lab and at home. In 10th pangborn sensory science symposium. Rio de Janeiro, Brazil.

Schlich, P., Pineau, N., Urbano, C., \& Visalli, M. (2013). Overview - multi-bites or multi-sips TDS with untrained subjects: A live demonstration on chocolates. In 10th pangborn sensory science symposium. Rio de Janeiro, Brazil.

Sokolowsky, M., Rosenberger, A., \& Fischer, U. (2015). Sensory impact of skin contact on white wines characterized by descriptive analysis, time-intensity analysis and temporal dominance of sensations analysis. Food Quality and Preference, 39, 285-297.

Stone, H., \& Sidel, J. L. (1993). Chapter 6 - descriptive analysis. In Sensory evaluation practices. London: Academic Press.

Thomas, A., Visalli, M., Cordelle, S., \& Schlich, P. (2015). Temporal drivers of liking. Food Quality and Preference, 40(Part B), 365-375.

Zorn, S., Alcaire, F., Vidal, L., Giménez, A., \& Ares, G. (2014). Application of multiplesip temporal dominance of sensations to the evaluation of sweeteners. Food Quality and Preference, 36, 135-143. 